\title{
Heparin-Coated Wiktor Stents in Human Coronary Arteries (MENTOR Trial)
}

\author{
Matty C.M. Vrolix, MD, Victor M. Legrand, MD, Johan H.C. Reiber, MD, PhD, \\ Gille Grollier, MD, Martin J. Schalii, MD, Philippe Brunel, MD, Louis Martinez-Elbal, MD, \\ Manuel Gomez-Recio, MD, Frits W.H.M. Bär, MD, Michel E. Bertrand, MD, PhD, \\ Antonio Colombo, MD, PhD, and Johannes Brachman, MD, \\ for the MENTOR Trial Investigators
}

The purpose of this study was to determine the feasibility, safety, and efficacy of elective stenting with heparincoated Wiktor stents in patients with coronary artery disease. In experimental studies, heparin coating has been shown to prevent subacute thrombosis and restenosis. Recently, a new method of heparin coating was developed, resulting in a more stable and predictable heparin layer on stent devices. This trial constitutes the first in-human use of this coating procedure, applied on the well-known Wiktor stent device. Heparin-coated Wiktor stent implantation was performed in 132 consecutive patients (132 lesions) in a multicenter international trial from September 1996 to February 1997. Forty-three percent of patients had unstable angina, $33 \%$ had previous myocardial infarction, and $10 \%$ had diabetes mellitus. Patients were followed for 12 months for occurrence of major adverse cardiovascular events, and $96 \%$ of the eligible patients underwent quantitative angiographic control at 6 months. Stent deployment was successful in $95.5 \%$ of lesions. Minimal lumen diameter increased by $1.67 \pm 0.48 \mathrm{~mm}$ (from $1.02 \pm 0.38 \mathrm{~mm}$

D espite important advances in the clinical use of coronary stents, there still are important limitations to the general applicability of this technique. Even with the use of antiplatelet regimen with aspirin and ticlopidine, the risk of (sub)acute stent thrombosis remains important. ${ }^{1}$ Furthermore, the use of ticlopidine carries a substantial risk of hematologic complications. $^{2}$ Therefore, a search for an effective method of stent surface passivation, eventually resulting in less thrombogenic risk and less need for concomitant medication, seems warranted. Data from animal work indicate that heparin-coated stents are associated with less acute thrombus formation, both in rabbit iliac $\operatorname{arteries}^{3}$ and in a porcine coronary model..$^{4,5}$ Previous

\footnotetext{
From the AZ St Jan, Genk, Belgium; CHU Sart Tilman, Liège, Belgium Heart Core, Leiden, The Netherlands; CHU, Caen, France; LUMC Leiden, Leiden, The Netherlands; CHU de Nantes, Nantes, France Hospital de la Princesa, Madrid, Spain; Academisch Ziekenhuis, Maastricht, The Netherlands; Université de Lille, Lille, France; Casa D Cura Columbus, Milan, Italy; and Medizinische Universitäts Klinik, Heidelberg, Germany. The study was supported in part by Medtronic Inc., Minneapolis, Minnesota. Manuscript received December 22 1999; revised manuscript received and accepted March 1, 2000.

Address for reprints: Matty C.M. Vrolix, MD, Hartcentrum Limburg Afd. Genk, Alg., Ziekenhuis, St Jan, Schiepse Bos 6, 3600 Genk, Belgium. E-mail:m.vrolix@ping.be.
}

before to $2.69 \pm 0.37 \mathrm{~mm}$ after the stent implantation). Mean percent diameter stenosis decreased from $67.4 \pm$ $11.3 \%$ before to $18.9 \pm 7.7 \%$ after the intervention. A successful intervention ( $<50 \%$ diameter stenosis and no major adverse cardiac events within 30 days) occurred in $97 \%$ of the patients. The subacute thrombosis rate was $0.8 \%$, which compares favorably with historical controls of this stent, and a low incidence of postprocedural increase in creatine kinase-MB was noted. At 6 months, event-free survival was $85 \%$ and angiographic restenosis rate was $22 \%$ with late loss of $0.78 \pm 0.69$ $\mathrm{mm}$ and a loss index of $0.48 \pm 0.44$. Heparin-coated Wiktor stents appeared to be an efficacious device to treat Benestent-like lesions, yielding angiographic and clinical results comparable to a heparin-coated PalmazSchatz stent. Despite its use in more complex lesions, the incidence of subacute thrombosis appeared to be lower than historical controls with a similar noncoated stent. (C) 2000 by Excerpta Medica, Inc.

(Am J Cardiol 2000;86:385-389)

clinical work with the heparin-coated Palmaz-Schatz stent (Johnson \& Johnson, Interventional Systems, Warren, New Jersey) showed the safety and the efficacy of the heparin-coating technique. ${ }^{6,7}$ Recently, a new coating technique was developed, resulting in a more stable binding of heparin onto the surface (more temperature resistant and longer shelf time). This coating technique was applied on the Wiktor GX stent (Wiktor, Medtronic, Inc., Minneapolis, Minnesota). After several biochemical, morphologic, and animal tests, ${ }^{8}$ it was decided to perform a multicenter clinical trial testing the safety and efficacy of this device in human coronary arteries.

\section{METHODS}

Wiktor GX balloon-expandable intracoronary stent: The balloon-expandable Wiktor stent used in the present study is constructed of a single tantalum wire (diameter $0.127 \mathrm{~mm}$ ) that is formed into a sinusoidal wave and wrapped into a helical coil structure. The prosthesis, $16 \mathrm{~mm}$ long, is premounted on a polyethylene balloon of a standard angioplasty catheter. The device was used under the Food and Drug Administration investigational device exemption status as part of a multicenter study. The study was approved by the ethical committee of each participating institution. 
Heparin-coating procedure: The heparin is covalently bound to the tantalum stent surface according to the Hepamed (Medtronic Bakken Research Center, Maastricht, The Netherlands) coating procedure (in contrast with the classic Carmeda coating procedure). In short, poly(vinylsiloxane) is covalently bound to the tantalum surface as a first layer. Using a radical polymerization process, a co-polymer is grafted to the pendant vinyl groups of the poly(vinylsiloxane) layer. The result is a hydrophilic co-polymer covalently bound to the first layer. Polyethyleneimine (third layer) is covalently bound to the carboxyl groups of the co-polymer in such a way that the polyamine interpenetrates the grafted co-polymer. As a fourth and last layer, heparin is covalently coupled to the polyamine using a reducing agent. ${ }^{9}$

Selection of patients: Eligible patients were those scheduled to undergo coronary angioplasty, who had 1 de novo lesion resulting in stable or unstable angina, without contraindications for platelet therapy with aspirin and ticlopidine, and who were suitable for stent implantation (lesions $\leq 12 \mathrm{~mm}$ in length and located in a vessel that was visually estimated at between $\geq 3$ and $\leq 4.5 \mathrm{~mm}$, supplying viable myocardium). Patients were excluded if a left main lesion was present, Thrombolysis In Myocardial Infarction (TIMI) flow was $<2$, if they had an acute myocardial infarction $<7$ days old, any thrombus present, an ostial lesion $(<12$ $\mathrm{mm}$ for right coronary artery, $<5 \mathrm{~mm}$ for left coronary artery), diffuse coronary disease, previous bypass on target vessel, lesion located in bypass graft, left ventricular ejection fraction $<40 \%$, and a lesion located at a bifurcation (diameter side branch $>50 \%$ of native vessel). The study was performed according to the Declaration of Helsinki and informed consent was obtained from all participating patients.

Implantation procedure: Before intervention, patients were pretreated with aspirin $(\geq 75 \mathrm{mg} /$ day $)$. In addition, a bolus of heparin (10,000 IU) was administered just before angioplasty, with supplemental boluses $(5,000 \mathrm{IU})$ for each additional hour of procedural time. Ticlopidine was preferably started 24 hours before the procedure. Stent implantation was performed according to standard clinical practice by the femoral route. Predilation was performed in every lesion. Subsequently, a premounted heparin-coated Wiktor stent with a diameter equivalent to or slightly $(<10 \%)$ greater than the mean reference diameter of the adjacent vessel was deployed at the nominal balloon inflation pressure. ${ }^{10}$ If necessary, further inflations up to $12 \mathrm{~atm}$ (with the stent delivery balloon) or $>12 \mathrm{~atm}$ (with another noncompliant or semicompliant balloon) were performed at the discretion of the investigator. ${ }^{11}$ Heparin was discontinued immediately after the procedure and sheaths were removed on the same day. All patients were treated with aspirin (75 to 300 $\mathrm{mg} /$ day) and ticlopidine ( 250 to $500 \mathrm{mg}$ /day) after the procedure. Ticlopidine was continued for $\geq 4$ weeks, providing absence of drug reactions. Creatine kinase and creatine kinase-MB values were assessed in all patients at 12 and 24 hours.
Clinical and angiographic follow-up: Patients were seen at the outpatient clinic at 30 days and at 6 months ( \pm 14 days) for interview, physical examination, and electrocardiograms. Hematologic monitoring was performed at 2 and 4 weeks. At 12 months, all patients were contacted (most by telephonic interview) for analysis of clinical events. At 6 months (before control angiography), an exercise test was performed. All eligible patients were scheduled for 6-month control angiography. Thus, in every patient an angiogram was performed at baseline, after intervention, and at 6-month follow-up. To standardize the method of data acquisition and analysis, all angiograms were analyzed in a core laboratory (Heart Core, Leiden, The Netherlands). The quantitative coronary angiographic measurements were assessed with the Cardiovascular Measurement System (QCA-CMS version 3.32, MEDIS, Leiden, The Netherlands). ${ }^{12-14}$

End points: The primary end point of this study was to assess the 30-day subacute and/or acute thrombosis rate. Secondary end points were both clinical, occurrence of major adverse cardiac events (death, myocardial infarction, and repeat intervention), and angiographic (restenosis rate, acute gain and late loss, success rate). Subacute and/or acute thrombosis was defined as the angiographic documentation of a complete occlusion (TIMI flow 0 or 1 ) or the angiographic documentation of a flow-limiting thrombus (TIMI flow 1 or 2). Death was defined to include all deaths, irrespective of cause. Myocardial infarction was diagnosed if there were new pathologic $\mathrm{Q}$ waves according to the Minnesota code ${ }^{15}$ and/or if there was an increase in serum creatine kinase to more than twice the normal value, along with increased myocardial isoenzyme levels. Repeat interventions were those involving a previously treated lesion following the initial procedure, which was judged to be complete when the guiding catheter was removed from the arterial sheath. Angiographic success rate was defined as a reduction in stenosis to $\leq 50 \%$. Procedural success was defined as angiographic success without major adverse cardiac events during hospitalization. Optimal stent placement was defined as residual stenosis $<20 \%$ after Wiktor stent placement as assessed by quantitative coronary angiography and TIMI 3 flow. Angiographic restenosis rate was defined as $\geq 50 \%$ diameter stenosis on follow-up angiography.

Statistical analysis: Continuous variables are expressed as means \pm SD. Discrete variables are expressed as counts and percentages.

\section{RESULTS}

Baseline characteristics: A total of 132 patients were enrolled at 10 European centers from September 1996 to February 1997. In 24 patients major violations regarding inclusion and exclusion criteria were observed, as assessed by an angiographic review committee. Protocol violations were (in ranking order): multivessel disease $(n=18)$; presence of thrombus $(n=3)$; diffuse disease $(n=1)$; ostial lesion $(n=1)$; and previous angioplasty $(n=1)$. Mean age was $57 \pm$ 


\begin{tabular}{|lr|}
\hline TABLE I Baseline Demographic Characteristics ( $\mathrm{n}=132)$ \\
\hline & No. (\%) \\
\hline Men & $106(80)$ \\
Women & $26(20)$ \\
Cardiac status & \\
Stable angina & $75(57)$ \\
CCS O & $13(10)$ \\
CCS I & $10(8)$ \\
CCS II & $27(20)$ \\
CCS III & $21(16)$ \\
CCS IV & $4(3)$ \\
Unstable angina & $57(43)$ \\
Myocardial infarction & \\
Q-wave & $28(21)$ \\
Non-Q-wave & $16(12)$ \\
Coronary bypass & $2(1)$ \\
Coronary angioplasty & $13(10)$ \\
Systemic hypertension & $44(33)$ \\
Hypercholesterolemia & $73(55)$ \\
Diabetes mellitus & $12(9)$ \\
Non-insulin dependent & $2(1)$ \\
Insulin dependent & \\
Smoker & $41(31)$ \\
Previous & $53(40)$ \\
Current & $60(45)$ \\
Family cardiac history & \\
\hline CCS = Canadian Cardiovascular Society. & \\
\hline
\end{tabular}

\begin{tabular}{|lr|}
\hline \multicolumn{2}{|l|}{ TABLE II Target Lesion Characteristics ( $\mathrm{n}=132)$} \\
\hline Characteristic & No. (\%) \\
\hline Morphology & \\
Concentric & $40(30)$ \\
Eccentric & $79(60)$ \\
Tandem & $1(1)$ \\
Multiple irregularities & $11(8)$ \\
Calcification & $12(9)$ \\
Lesion type & \\
A & $28(21)$ \\
B1 & $72(54)$ \\
B2 & $30(23)$ \\
C & $2(1)$ \\
Coronary artery & \\
Left anterior descending & $59(45)$ \\
Circumflex & $20(15)$ \\
Right & $53(40)$ \\
TIMl flow before angioplasty & \\
0 & $0(0)$ \\
1 & $1(1)$ \\
2 & $10(7)$ \\
3 & $121(92)$ \\
\hline
\end{tabular}

11 years. Patient baseline clinical and angiographic characteristics are listed in Tables I and II.

Stent implantation procedure: In total, 134 stent implantations were attempted in 132 patients (Table III). Of these, 128 stent deliveries were considered technically successful, yielding a stent delivery success rate of $96 \%$. The 6 delivery failures were due to unability to cross the lesion. In 2 patients the stent had to be deployed proximal to the lesion. In 4 patients, the stent was removed; 3 of these patients were treated with additional angioplasty and in the fourth patient a Palmaz-Schatz stent could also not be deployed; this patient underwent elective bypass surgery. Mean stent

\begin{tabular}{|lr|}
\hline TABLE III Stent Implantation Data & \\
\hline No. of stents used & 134 \\
No. of stents implanted & $130(97 \%)$ \\
$3.0 \mathrm{~mm}$ & $43(33 \%)$ \\
$3.5 \mathrm{~mm}$ & $61(47 \%)$ \\
$4.0 \mathrm{~mm}$ & $20(15 \%)$ \\
$4.5 \mathrm{~mm}$ & $6(5 \%)$ \\
No. of inflations before dilation & $1(1 \%)$ \\
0 & $64(48 \%)$ \\
1 & $55(42 \%)$ \\
2 & $12(9 \%)$ \\
$\geq 3$ & \\
No. of inflations at stent deployment & $65(50 \%)$ \\
1 & $46(35 \%)$ \\
2 & $13(10 \%)$ \\
3 & $4(3 \%)$ \\
$\geq 4$ & $8(6 \%)$ \\
High-pressure after deployment $>12 \mathrm{~atm})$ & $13(10 \%)$ \\
With stent delivery balloon & \\
With other balloon &
\end{tabular}

TABLE IV Cumulative Clinical Events at 30 Days, Six Months, and 12 Months in All 128 Patients With a Wiktor Hepamed Stent

\begin{tabular}{|c|c|c|c|}
\hline \multirow[b]{2}{*}{ Adverse Events } & \multicolumn{3}{|c|}{ All Implants ( $n=128$ ) } \\
\hline & $\begin{array}{l}\text { Day } \\
0-1 \mathrm{mo}\end{array}$ & $\begin{array}{l}\text { Day } \\
0-6 \text { mo }\end{array}$ & $\begin{array}{c}\text { Day } \\
0-12 \mathrm{mo}\end{array}$ \\
\hline Death & $2(1.6 \%)$ & $2(1.6 \%)$ & $2(1.6 \%)$ \\
\hline $\begin{array}{l}\text { Q-wave myocardial } \\
\text { infarction }\end{array}$ & 0 & 0 & 0 \\
\hline $\begin{array}{l}\text { Non-Q-wave myocardial } \\
\text { infarction }\end{array}$ & $1(0.8 \%)$ & $1(0.8 \%)$ & $1(0.8 \%)$ \\
\hline $\begin{array}{l}\text { Coronary artery bypass } \\
\text { grafting }\end{array}$ & 0 & $1(0.8 \%)$ & $3(2.3 \%)$ \\
\hline Repeat angioplasty & $1(0.8 \%)$ & $16(12.5 \%)$ & $18(14.1 \%)$ \\
\hline Patients with event & $4(3.1 \%)$ & 19 (14.8\%) & $21(16.4 \%)$ \\
\hline
\end{tabular}

size was $3.46 \pm 0.41 \mathrm{~mm}(3.0$ to 4.5$)$ with $80 \%$ of the stents mounted on a $\leq 3.5-\mathrm{mm}$ balloon. The mean balloon inflation pressure during predilation was $9 \pm$ $3 \mathrm{~atm}$; only 1 patient did not undergo predilation. In $87 \%$ of the patients $\leq 2$ balloon inflations were performed for stent deployment. Mean stent implantation pressure was $11 \pm 3 \mathrm{~atm}$ (range 6 to 19) for a total inflation time of $63.4 \pm 41$ seconds.

Clinical events: Four patients $(3.1 \%)$ had a major adverse cardiac event in the first month after heparincoated Wiktor stent implantation (Table IV). Three of these patients were protocol violators (multivessel disease [ 3 patients], thrombus [ 1 patient]). Two patients with multivessel disease died. The first patient, an 82-year-old woman, had a stent placed in the proximal right coronary artery. A few hours later, the patient became ischemic; control angiography showed a perfect stent result, but an acute occlusion of the distal circumflex artery. Attempts to reopen the circumflex artery resulted in contrast overload with pulmonary edema and cardiogenic shock. The second patient had significant 2-vessel disease with a thrombus at the dilation site before stenting. The patient had unevent- 


\begin{tabular}{|c|c|c|c|}
\hline & Before & After & $\begin{array}{c}\text { 6-mo } \\
\text { Follow-Up }\end{array}$ \\
\hline No. of lesions & 116 & 119 & 110 \\
\hline $\begin{array}{l}\text { Reference vessel } \\
\text { diameter (mm) }\end{array}$ & $3.17 \pm 0.54$ & $3.33 \pm 0.47$ & $3.17 \pm 0.52$ \\
\hline $\begin{array}{r}\text { Minimum luminal } \\
\text { diameter }(\mathrm{mm})\end{array}$ & $1.02 \pm 0.38$ & $2.69 \pm 0.37$ & $1.92 \pm 0.71$ \\
\hline $\begin{array}{l}\text { Diameter stenosis } \\
(\%)\end{array}$ & $67.4 \pm 11.3$ & $18.9 \pm 7.7$ & $39.9 \pm 18.0$ \\
\hline $\begin{array}{l}\text { Obstruction length } \\
(\mathrm{mm})\end{array}$ & $11.5 \pm 4.3$ & $15.3 \pm 3.4$ & $15.4 \pm 3.9$ \\
\hline Restenosis rate (\%) & & & $21.8 \%$ \\
\hline Acute gain (mm) & & $1.67 \pm 0.48$ & \\
\hline Net gain $(\mathrm{mm})$ & & & $0.89 \pm 0.76$ \\
\hline Late loss (mm) & & & $0.78 \pm 0.69$ \\
\hline Loss index & & & $0.48 \pm 0.44$ \\
\hline
\end{tabular}

ful stenting but suddenly collapsed at home at day 5 . No autopsy was performed. One patient had a thrombotic stent occlusion 3 hours after stenting, probably related to an untreated distal dissection that became occlusive after the procedure. In this patient, 2 additional stents (1 NIR stent [Medinol, Natick, Massachusetts] and 1 AVE stent [Arterial Vascular Engineering, Santa Rosa, California]) were implanted distal to the treated site. One patient had a non-Q-wave myocardial infarction the day after the procedure. All the remaining patients $(n=124)$ were event free at 30 days, resulting in an event-free rate of $97 \%$.

The 6-month target lesion revascularization rate was $17 \%$. One patient underwent elective coronary artery bypass grafting for recurrent angina 6 weeks after stenting and repeat coronary angioplasty was performed in 15 patients (12\%), resulting in an eventfree survival of $85 \%$. Ninety-five percent of surviving patients were either asymptomatic or had mild stable angina (Canadian Cardiovascular Society class I or II).

At 12-month follow-up (98\% complete) 4 additional reinterventions for revascularization in the target lesion were undertaken. Two patients underwent coronary artery bypass grafting and 2 patients were dilated, resulting in an event-free survival at 1 year of $84 \%$.

Angiographic results: Quantitative coronary angiography in $\geq 1$ angiographic projection was possible in 116 patients $(94 \%)$ before stenting, in 119 patients (97\%) after stenting, and in 110 patients $(89 \%)$ at follow-up. Data on pre- and postprocedural reference diameters, minimal luminal diameter, and percent diameter stenosis are listed in Table V. When compared with Benestent II data these diameters are remarkably similar (Table VI). The reference diameter was $<3.0$ $\mathrm{mm}$ in $38 \%,<2.75 \mathrm{~mm}$ in $21 \%$, and $<2.5 \mathrm{~mm}$ in $10 \%$ of the patients. The average diameter stenosis at baseline was $67 \%$, which was reduced after stenting to $19 \%$ (range $-16 \%$ to $42 \%$ ). In all cases, final diameter stenosis was $<50 \%$, leading to angiographic success rate of $100 \%$. An optimal stent placement was achieved in only 71 cases $(60 \%)$. The mean stent-toartery dimension ratio was 1.11 , defining a mean stent oversizing by $11 \%$.

Six-month angiograms were obtained in 123 pa- tients (96\%), of which 110 films were suitable for quantitative coronary angiography. The restenosis rate was $22 \%$ (24 of 110 patients). Minimal luminal diameter increased from $1.02 \mathrm{~mm}$ before treatment to 1.92 $\mathrm{mm}$ at 6 months, representing a net gain of $0.89 \mathrm{~mm}$. Late loss was calculated as $0.78 \mathrm{~mm}$, with a loss index of 0.48 . Of the 24 patients with $>50 \%$ stenosis at follow up, only 10 patients were symptomatic; interestingly, 9 of 24 patients had a percent diameter stenosis at follow-up between $50 \%$ to $60 \%$ that was mostly diffuse but only 2 patients were symptomatic.

\section{DISCUSSION}

The present study assesses the utility of a new method of heparin coating, resulting in more predictable activity over time. It is the first prospective study using the heparin-coated Wiktor stent for the treatment of Benestent-like lesions. Although many patients $(18.2 \%)$ did not meet the strict angiographic criteria defined in the protocol to fullfill the lesion characteristics as those included in the Benestent trial, it was decided to keep them in the analysis even if this could influence both the early and late clinical and/or angiographic results.

Principles of the heparin coating: Contact of blood with a foreign surface is known to result in a multiplicity of phenomena, including protein deposition and activation of complement system and clotting cascade, eventually leading to thrombus formation. Electropolishing of the stent resulting in passivation and a smooth surface has been shown to reduce the incidence of stent thrombosis. ${ }^{16}$ Nevertheless, stent thrombosis remains a potential problem, particularly when treating total occlusion, acute myocardial infarction, or smaller vessels. Therefore, a number of materials are evaluated as potential thromboresistant stent coatings (hydrogel, polyurethanes). A heparincoated surface with its end attached to the stent proved to be superior in thrombosis models and was first used in the Benestent II study. ${ }^{7}$ Heparin-coated surfaces were evaluated before in various devices where thromboresistance was of clinical value, such as arteriovenous shunts, arterial filters, oxygenators, and vascular endoprosthesis. ${ }^{17-19}$

The principle anticoagulant mechanism of heparin is the interaction with antithrombin III, accelerating the inactivation of thrombin or other coagulation factors. The problem with surface coating is that the heparin molecule has to remain biologically active (i.e., the active sequence has to remain unaltered). For the present study, heparin was covalently bound to the tantalum stent surface according to the Hepamed coating procedure. In brief, this method results in a stronger and more stable binding of heparin to the stent surface, resulting in a more stable antithrombin III activity over time. ${ }^{9}$

Heparin coating in the ticlopidine era: The Full Anticoagulation versus Aspirin and Ticlopidine (FANTASTIC) study has definitely shown a reduction of subacute stent occlusion for the Wiktor stent with the use of ticlopidine. ${ }^{1}$ However, when closely examining the results, there was an incidence of $2.4 \%$ of acute 
TABLE VI Angiographic Data in Heparin-Coated Stent Trials

\begin{tabular}{|c|c|c|c|c|c|c|c|c|}
\hline & No. & $\begin{array}{c}\text { Reference } \\
\text { Vessel } \\
\text { Diameter Before } \\
\text { PTCA }\end{array}$ & $\begin{array}{c}\text { Minimum } \\
\text { Luminal } \\
\text { Diameter Before } \\
\text { PTCA }\end{array}$ & Acute Gain & Late Loss & Net Gain & Loss Index & $\begin{array}{c}\text { Percent } \\
\text { Diameter } \\
\text { Stenosis } \\
>50 \%\end{array}$ \\
\hline Benestent II pilot & 203 & $3.16 \pm 0.41$ & $1.10 \pm 0.31$ & $1.67 \pm 0.38$ & $0.68 \pm 0.50$ & $0.97 \pm 0.59$ & $0.41 \pm 1.18$ & $13 \%$ \\
\hline $\begin{array}{l}\text { Benestent II stent arm } \\
\text { (angio subgroup) }\end{array}$ & 207 & $2.96 \pm 0.54$ & $1.08 \pm 0.28$ & $1.61 \pm 0.39$ & $0.80 \pm 0.54$ & $0.80 \pm 0.62$ & $0.50 \pm 0.10$ & $6 \%$ \\
\hline MENTOR & 110 & $3.17 \pm 0.54$ & $1.02 \pm 0.38$ & $1.67 \pm 0.48$ & $0.78 \pm 0.69$ & $0.89 \pm 0.76$ & $0.48 \pm 0.44$ & $21.8 \%$ \\
\hline
\end{tabular}

stent occlusion in the antiplatelet group and a 3.7\% incidence of non-Q-wave infarction (defined as an increase of creatine kinase $>2$ times upper limit of normal). In this study, a $0.8 \%$ rate of acute occlusion and $0.8 \%$ rate of non-Q-wave infarction both suggest a clinical benefit for the heparin-coated stent. However, it has to be admitted that in the FANTASTIC study all types of stent placement, elective and bailout, were allowed, whereas in the present study only Benestent-like lesions, at least in theory, could be treated. Further evidence for a possible effect of the heparin coating comes from the prospective creatine kinase and creatine kinase-MB data. In the present trial, the increase of creatine kinase/creatine kinase-MB was $0.8 \%$ (comparable to Benestent II), which compares favorably to other prospective nonheparin-coated stent trials ( $8 \%$ to $15 \%) .{ }^{20}$ This apparent reduction in creatine kinase can be attributed to the heparin coating, although the lack of side branch occlusion with this rather open stent design could also explain this observation.

Role of heparin coating in stent restenosis: In this trial, as well as in the Benestent trial, the magnitude of restenosis, late loss, and loss index is similar to that observed in angiographic trials using noncoated stents (Table VI). ${ }^{21}$ The failure to prevent restenosis with heparin coating indicates that thrombin generation is not the sole activator of neointimal proliferation. Although thrombin has been shown to have potent direct and indirect mitogenic effects, ${ }^{22}$ the results of this study indicate that restenosis after stent implantation is a multifaceted problem that cannot be overcome only by reducing or inhibiting early thrombus formation.

Acknowledgment: We are grateful to Sabine Jacobs for her expert assistance in data collection and monitoring.

1. Bertrand ME, Legrand V, Boland J, Fleck E, Bonnier J, Emmanuelson H, Vrolix M, Missault L, Chierchia S, Casaccia M, Niccoli L, Oto A, White C, Webb-Peploe M, Van Belle E, Mc Fadden EP. Randomized multicenter comparison of conventional anticoagulation versus antiplatelet therapy in unplanned and elective coronary stenting. The Full Anticoagulation Versus Aspirin and Ticlopidine (FANTASTIC) Study. Circulation 1998;98:1597-1603.

2. McTavish D, Faulds D, Goa KL. Ticlopidine: an updated review of its pharmacology and therapeutic use in platelet dependent disorders. Drugs 1990 40: $238-259$.

3. Baily SR, Paige S, Lunn AC, Palmaz J. Heparin coating of endovascular stents decreases subacute thrombosis in a rabbit model (abstr). Circulation 1992; 86 (suppl I):I-186. Abstract.

4. Hardhammer PA, Van Beusekom H, Emanuelsson HV, Hofma SH, Albertsson PA, Verdouw PD, Boersma E, Serruys PW, Van der Giessen WJ. Reduction of thrombotic events using heparin-coated Palmaz-Schatz stents in normal porcine coronary arteries. Circulation 1996; 93:423-430.

5. De Scheerder I, Wang K, Wilczek K, Meuleman D, Van Amsterdam R, Vogel G, Piessens J, Van de Werf F. Experimental study of thrombogenicity and foreign body reaction induced by heparin-coated coronary stents. Circulation 1997;95: 1549-1553.

6. Serruys PW, Emanuelsson H, van der Giessen W, Lunn AC, Kiemeney F, Macaya C, Rutsch W, Heyndrickx G, Suryapranata H, Legrand V, et al, on behalf of the Benestent-II Study Group. Heparin-coated Palmaz-Schatz stents in human coronary arteries. Early outcome of the Benestent-II Pilot Study. Circulation 1996;93:412-422.

7. Serruys PW, Van Hout B, Bonnier H, Legrand V, Garcia E, Macaya C, Sousa E, van der Giessen W, Colombo A, Seabra-Gomes R, et al. Randomized comparison of implantation of heparin-coated stents with balloon angioplasty in selected patients with coronary artery disease (Benestent II). Lancet 1998;352: 673-681.

8. Ahn YK, Jeong MH, Kim JW, Kim SH, Cho JH, Cho JG, Park CS, Juhng SW, Park JC, Kang JC. Preventive effects of the Heparin-coated stent on restenosis in the porcine model. Cath Cardiovasc Interv1999;48:324-330.

9. Blezer R, Cahalen L, Cahalan PT, Lindhout T. Heparin coating of tantalum coronary stents reduces surface thrombin generation but not factor IXa generation. Blood Coagul Fibrinol1998;9:435-440.

10. Vrolix M, Piessens J, for the European Wiktor Stent Study Group. Usefulness of the Wiktor stent for treatment of threatened or acute closure complicating coronary angioplasty. Am J Cardiol1994;73:737-741.

11. Yang P, Gyongyosi M, Hassan A, Heyer G, Klein W, Luha O, Maurer E, Mühlberger V, Pachinger O, Sochor H, et al, on behalf of the Austrian Wiktor Stent Study Group. Short- and long-term outcomes of Wiktor stent implantation at low versus high pressures. Am J Cardiol 1999;84:644-649.

12. Reiber JHC, von Land CD, Koning G, van der Zwet PMJ, van Houdt RCM, Schalij MJ, Lespérance J. Comparison of accuracy and precision of quantitative coronary arterial analysis between cinefilm and digital systems. In: Reiber JHC, Serruys PW, eds. Progress in Quantitative Coronary Arteriography. Dordrecht: Kluwer Academic Publishers, 1994:67-85.

13. Reiber JHC, Schiemanck LR, van der Zwet PMJ, Goedhart B, Koning G, Lammertsma M, Danse M. Gerbrands JJ, Schalij MJ, Bruschke AVG. State of the art in quantitative coronary arteriography as of 1996. In: Reiber JHC, van der Wall EE, eds. Cardiovascular Imaging. Dordrecht: Kluwer Academic Publishers, 1996:39-56.

14. van der Zwet PMJ, Reiber JHC. A new approach for the quantification of complex lesion morphology: The gradient field transform. Basic principles and validation results. I Am Coll Cardiol 1994;24:216-24.

15. Blackburn H, Keys A, Simonson E, Rautaharju P, Punsars R. The electrocardiogram in population studies: a classification system. Circulation 1960;21: $1160-1175$.

16. Balcon R, Beyar R, Chierchia S, De Scheerder I, Hugenholtz PG, Kiemeneij F, Meier B, Meyer J, Monassier JP, Wijns W. Recommendations on stent manufacture, implantation and utilization. Study Group of the Working Group on Coronary Circulation. Eur Heart J1997;18:1536-1547.

17. Lelah, Lambracht LK, Cooper SL. A canine ex vivo series shunt experiment for evaluating thrombus deposition on polymer surfaces. J Biochem Mater Res 1984;18:475-496.

18. Palenzo DA, Kurusz M, Butler BD. Surface tension effects of heparin coating on arterial line filters. Perfusion 1990;5:277-284.

19. Hsu LC. Principles of heparin-coating techniques. Perfusion 1991;6:209219.

20. Abdelmeguid A, Topol E. The myth of the myocardial 'infarctlet' during percutaneous revascularization procedures. Circulation 1996;94:3369-3375.

21. Serruys PW, Grines CL, Stone GW, Garcia E, Kiemeney F, Morice MC, Sousa JE, Hamm C, Constantini C, Lefevre T, et al, for the PAMI/STENT Study Group. Stent implantation in acute myocardial infarction using a heparin-coated stent: a pilot study as a preamble to a randomized trial comparing balloon angioplasty and stenting. Int J Cardiovasc Intervent 1998;1:19-27.

22. Schwartz RS, Edwards WD, Camrud AR. Developmental stages of restenotic neointimal hyperplasia following porcine coronary injury. A morphologic review. J Vasc Med Biol 1993;4:70-78. 